\title{
Identifying Sources of Volatile Organic Compounds and Aldehydes in a High Performance Building
}

\author{
Anna C. Ortiz ${ }^{2}$, Marion Russell ${ }^{1}$, Wen-Yee Lee $^{2}$ \\ Michael G. Apte ${ }^{1}$, and Randy Maddalena ${ }^{1}$ \\ ${ }^{1}$ Environmental Energy Technologies Division \\ Indoor Environment Department \\ Lawrence Berkeley National Laboratory \\ Berkeley, CA 94720 \\ ${ }^{2}$ University of Texas at El Paso \\ 500 W. University Ave. \\ El Paso, TX 79968
}

September 20, 2010

This work was conducted as part of, and with support from, the Faculty and Student Teams (FaST) internship program, which is a collaboration between Department of Energy's Office of Science Workforce Development for Teachers and Scientists and the National Science Foundation. The FaST program is managed at Lawrence Berkeley National Laboratory by the Center for Science and Engineering Education. The work was sponsored by the Assistant Secretary for Energy Efficiency and Renewable Energy, Building Technologies Programs of the U.S. Department of Energy under Contract DEAC02-05CH11231. 


\section{ERNEST ORLANDO LAWRENCE BERKELEY NATIONAL LABORATORY}

\section{Identifying Sources of Volatile Organic Compounds and Aldehydes in a High Performance Building}

Anna C. Ortiz, Marion Russell, Wen-Yee Lee, Michael G. Apte, and Randy Maddalena

Environmental Energy

Technologies Division

September 2010

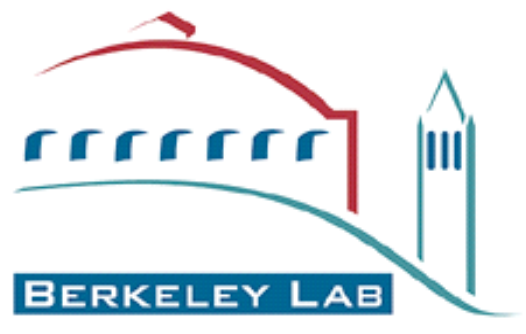




\section{DISCLAIMER}

This document was prepared as an account of work sponsored by the United States Government. While this document is believed to contain correct information, neither the United States Government nor any agency thereof, nor The Regents of the University of California, nor any of their employees, makes any warranty, express or implied, or assumes any legal responsibility for the accuracy, completeness, or usefulness of any information, apparatus, product, or process disclosed, or represents that its use would not infringe privately owned rights. Reference herein to any specific commercial product, process, or service by its trade name, trademark, manufacturer, or otherwise, does not necessarily constitute or imply its endorsement, recommendation, or favoring by the United States Government or any agency thereof, or The Regents of the University of California. The views and opinions of authors expressed herein do not necessarily state or reflect those of the United States Government or any agency thereof, or The Regents of the University of California.

\footnotetext{
Ernest Orlando Lawrence Berkeley National Laboratory is an equal opportunity employer.
} 


\section{ACKNOWLEDGMENTS}

This work was conducted as part of, and with support from, the Faculty and Student Teams (FaST) internship program, which is a collaboration between Department of Energy's Office of Science Workforce Development for Teachers and Scientists and the National Science Foundation. The FaST program is managed at Lawrence Berkeley National Laboratory by the Center for Science and Engineering Education. The work was sponsored by the Assistant Secretary for Energy Efficiency and Renewable Energy, Office of Building Technology, State, and Community Programs, of the U.S. Department of Energy under Contract No. DE-AC0205CH11231. The authors are grateful to our colleagues Hugo Destaillats and Henry Willem for a thorough review of this report.

I would like to thank my mentor Randy Maddalena and associate mentor Marion Russell. I would also like to thank Wen-Yee Lee for all her support and Michael Apte for his collaboration (A.C. Ortiz). 
This page is intentionally blank. 
ACKNOWLEDGMENTS ............................................................................................................................II

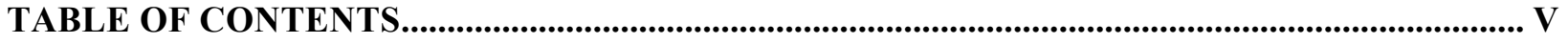

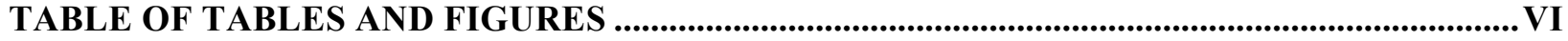

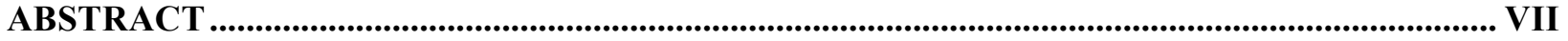

INTRODUCTION

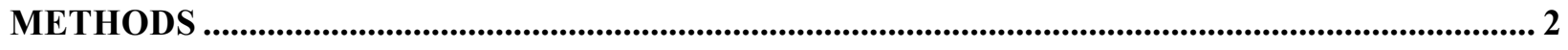

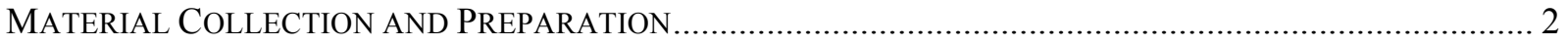

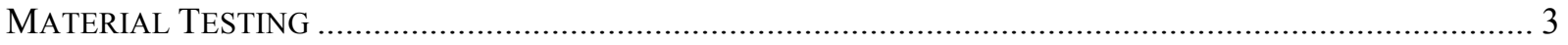

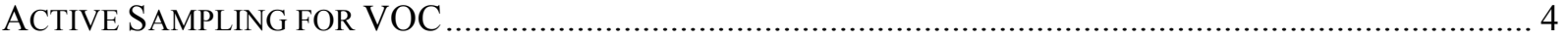

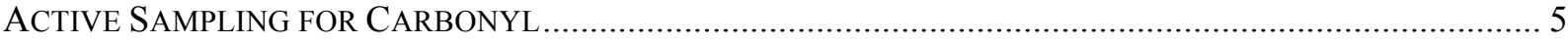

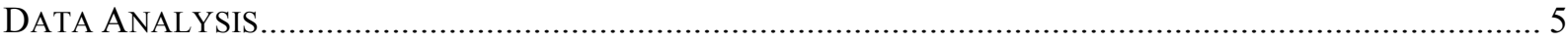

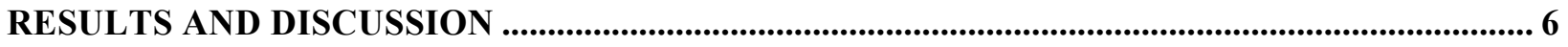

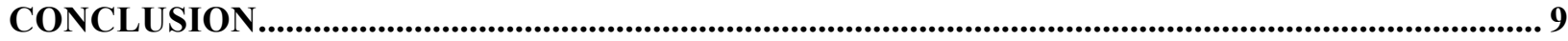

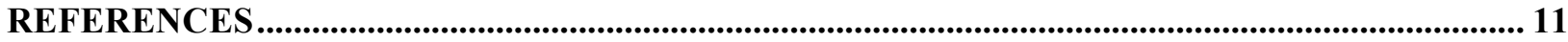




\section{TABLE OF TABLES}

Table 1. PBC Building Material Samples

Table 2. Measured air concentrations $\left(\mu \mathrm{g} \mathrm{m}^{-3}\right)$ of identified chemicals in test chamber after 24-hour conditioning period.

Table 3. Standard Emission Factors $\left(\mu \mathrm{g} \mathrm{m}^{-2} \mathrm{~h}^{-1}\right)$ for PBC materials determined after 7-days conditioning

Table 4. Building specific parameters used to estimate room air concentrations 17

Table 5. Comparison of estimated to measured formaldehyde in PBC 17

\section{TABLE OF FIGURES}

Figure 1. Example of prepared material samples installed in conditioning chambers prior to testing. Chambers are shown with lids removed.

Figure 2. Photograph of emission chambers housed inside controlled environment oven. 18

Figure 3. Total VOC emission factors (listed in parenthesis) for each material stacked in order of decreasing contribution to the emission stream. The results for formaldehyde are listed separately (see Figure 4) and are not included in this chart.

Figure 4. Comparison of formaldehyde emission from the different wall covering materials showing that the new wood is the primary source of formaldehyde and the use of polish does not significantly affect the measured emission factors. Actual values of the emission factors are listed above the column. New wood with new polish was aged 21 days while the other materials were aged 7 days. 20

Figure 5. Aging of formaldehyde emissions for polished and unfinished surface of new wood compared to the emissions from the new wood sample with no applied polish. The experiments were run in the order 1) new wood new polish (diamonds) and new wood no polish (asterisk); 2) unpolished side (squares); 3) return to polished side of new wood new polish (triangle); 4) return to unpolished side (cross). During conditioning and testing of the polished side, the unpolished side was covered and visa versa. 


\section{ABSTRACT}

The developers of the Paharpur Business Center (PBC) and Software Technology Incubator Park in New Delhi, India offer an environmentally sustainable building with a strong emphasis on energy conservation, waste minimization and superior indoor air quality (IAQ). To achieve the IAQ goal, the building utilizes a series of air cleaning technologies for treating the air entering the building. These technologies include an initial water wash followed by ultraviolet light treatment and biolfiltration using a greenhouse located on the roof and numerous plants distributed throughout the building. Even with the extensive treatment of makeup air and room air in the $\mathrm{PBC}$, a recent study found that the concentrations of common volatile organic compounds and aldehydes appear to rise incrementally as the air passes through the building from the supply to the exhaust. This finding highlights the need to consider the minimization of chemical sources in buildings in combination with the use of advanced air cleaning technologies when seeking to achieve superior IAQ. The goal of this project was to identify potential source materials for indoor chemicals in the PBC. Samples of building materials, including wood paneling (polished and unpolished), drywall, and plastic from a hydroponic drum that was part of the air cleaning system, were collected from the building for testing. All materials were collected from the PBC building and shipped to the Lawrence Berkeley National Laboratory (LBNL) for testing. The materials were pre-conditioned for two different time periods before measuring material and chemical specific emission factors for a range of VOCs and Aldehydes. Of the six materials tested, we found that the highest emitter of formaldehyde was new plywood paneling. Although polish and paint contribute to some VOC emissions, the main influence of the polish was in altering the capacity of the surface to accumulate formaldehyde. Neither the new nor aged polish contributed significantly to formaldehyde emissions. The VOC emission stream (excluding formaldehyde) was composed of up to 18 different chemicals and the total VOC emissions ranged in magnitude from $7 \mu \mathrm{g} / \mathrm{m}^{2} / \mathrm{h}$ (old wood with old polish) to $>500 \mu \mathrm{g} / \mathrm{m}^{2} / \mathrm{h}$ (painted drywall). The formaldehyde emissions from drywall and old wood with either new or old polish were $\sim 15 \mu \mathrm{g} / \mathrm{m}^{2} / \mathrm{h}$ while the new wood material emitted $>100 \mu \mathrm{g} / \mathrm{m}^{2} / \mathrm{h}$. However, when the projected surface area of each material in the building was considered, the new wood, old wood and painted drywall material all contributed substantially to the indoor formaldehyde loading while the coatings contributed primarily to the VOCs. 


\section{INTRODUCTION}

Features of the seven-story Paharpur Business Center (PBC) and Software Technology Incubator Park in New Delhi India have been described [1,2]. A notable feature of the building is the stated goal of providing a healthy work environment for building occupants with specific interest in maintaining superior indoor air quality (IAQ) [1]. To achieve this goal, the building utilizes several innovative air cleaning technologies, such as air washing to remove the more polar volatile contaminants, bio-filtration of building makeup air using an enclosed rooftop greenhouse with a high density of potted plants, passive treatment of indoor air using a large number of potted plants distributed throughout the building, dedicated secondary heating, ventilation and air conditioning (HVAC) air handling units on each floor with re-circulating high efficiency filtration and ultraviolet light treatment of heat exchanger coils, and air exhaust via the restrooms located on each floor. The idea of using potted plants to remove VOCs from the indoor environment was originally introduced by Wolverton et.al. [3, 4]. In addition to treating the air, the PBC management recognizes the importance of reducing potential sources of indoor chemicals by providing environmentally friendly cleaning products exclusively for the building and selecting certain materials during renovations including a combination of stone, tile and 'zero VOC' floor covering and solid sawn wood materials for trim, paneling and furniture, with minimal use of composite wood products [2].

A recent short-term field study collected indoor air quality measurements at the PBC to investigate the performance of the biofiltration air cleaning system [2]. The study focused primarily on VOCs and aldehydes and collected measurements at several locations in the building representing the transfer pathway of air moving through the building starting on the roof outdoors and following through the rooftop greenhouse, indoors on two floors, and at the building exhaust locations. The study found that for most contaminants, the levels of common indoor VOCs and aldehydes generally increased as the air moved through the building, indicating the presence of indoor sources. The study concluded that even with the extensive effort given to maintaining superior IAQ, the building still had concentrations of VOCs and carbonyls similar to that found in other office buildings. However, the authors point out that given the outdoor air quality in New Delhi compared to the outdoor air quality where the comparative IAQ studies have been carried out for other office buildings, the findings of the 
short-term study may indicate some added benefit of the biofiltration-based air cleaning technology.

The increase in concentration for several VOCs and carbonyls as the air moved through the building indicated the presence of an indoor source for these chemicals. The contribution of indoor chemicals from different building materials and building contents have been investigated for a range of building types [5-8] and typical concentrations measured in these buildings have been summarized [9-14]. The purpose of this project was to investigate the potential source(s) of VOCs and carbonyls in the PBC. Following the short-term testing [2], the building managers identified several potential sources of indoor contaminants including composite wood paneling, painted gypsum board walls and high density plastic barrels used as hydroponic containers for the biofiltration-based air cleaning technology. Both new and aged ( $\sim 20$ year old) plywood wall paneling was present in the building and the paneling was coated with a clear polish. The goal of this study was to measure material specific emission factors for VOCs and carbonyls and characterize the potential influence of the polish coating on the wood panel material.

\section{METHODS}

\section{Material Collection and Preparation}

All building materials that were tested for emissions were harvested from the PBC building, double wrapped in foil and shipped directly to Lawrence Berkeley National Laboratory for testing. A description of each of the material samples is provided in Table 1. All samples except for the hydroponic drum were cut to $0.023 \mathrm{~m}^{2}$ (six inches square). In the laboratory, the sides and backs of the material were sealed with aluminum tape and stainless steel backing plates, respectively, to leave only the front face of the material exposed for testing. Each sample was placed individually in 6-liter stainless steel conditioning chamber as illustrated in Figure 1. The conditioning chambers were closed with Teflon lined lids and held at approximately $22{ }^{\circ} \mathrm{C}$ and $50 \%$ relative humidity $(\mathrm{RH})$ to precondition the materials prior to sampling. For new materials, samples are typically preconditioned to allow the emissions to drop to a more relevant value for estimating long-term emission rates. For materials that are allowed to age in the environment, the conditioning period is important to allow chemicals that have partitioned into 
the material from the environment, e.g., chemicals that are not indigenous to the material, to offgas so that the measured emission rates are relevant to the material being tested. The conditioning chambers were ventilated with carbon/HEPA filtered air at a rate of $250 \mathrm{cc} / \mathrm{min}(2.5$ air changes per hour or $0.65 \mathrm{~m}^{3}{ }_{\text {[air] }} / \mathrm{m}^{2}{ }_{\text {[exposed surface area] }} /$ hour).

\section{Material Testing}

The emission testing generally followed California Specification 01350 [15] and ASTM Standard Guide D-6007-02 [16] using small emission chambers. The approach has been used for a wide range of materials measuring both VOCs and carbonyls as described previously [8, 17] and as summarized below.

Four emission chambers installed in a controlled environment oven provide an isolated environment with constant temperature and humidity. The constant humidity was maintained by splitting the flow of dry $(<5 \% \mathrm{RH})$ carbon/HEPA filter air with a portion of the air bubbling through a water bath then re-mixed to achieve the desired humidity for air flowing through each chamber. The chambers, shown in Figure 2, are made of stainless steel and all interior surfaces are coated with Sulfinert ${ }^{\circledR}$ coating to minimize chemical interaction with chamber walls. The chambers are $10.75 \mathrm{~L}$ and are operated with an approximate ventilation rate of 1 liter per minute

equivalent to 5.6 air changes per hour $(\mathrm{ACH})$, or $2.6 \mathrm{~m}^{3}{ }_{\text {[air] }} / \mathrm{m}^{2}$ [exposed surface area] $/$ hour). The standard tests are operated at $25^{\circ} \mathrm{C}$ and $50 \% \mathrm{RH}$. After being pre-conditioned, each test material was transferred to the test chamber and placed on Sulfinert ${ }^{\circledR}$ treated screens resting slightly below the midpoint of the chamber.

Each material was allowed to equilibrate in the test chamber for at least 30 minutes after being transferred from the conditioning chamber before testing. Once equilibrated, the air samples were collected directly from the test chamber and analyzed for VOC and Aldehydes (ALD) as described below. The materials were first tested after 24 hours of conditioning, and then again after at least seven days of conditioning. The first sampling period was used to get information on upper bound emission rates and allow for the identification of the mix of chemicals in the emission stream. The second sampling period, after seven days conditioning, provides the emission factors that are more relevant to the long-term emission pattern. Additional 
measurements were collected for the new wood with new polish to further understand how the polish affects the emissions from the material.

\section{Active Sampling for VOC}

VOC samples were collected and analyzed following the U.S. Environmental Protection Agency (USEPA) Method TO-17 [18]. VOC air samples were collected directly from the chambers by drawing chamber air through multi-sorbent tubes with a primary bed of TenaxTA ${ }^{\circledR}$ sorbent backed with a section of Carbosieve ${ }^{\circledR}$. A peristaltic pump was used to pull the air through the sample tubes at a rate of approximately $100 \mathrm{~mL} / \mathrm{min}$ for 1 hour. The flow was measured using a DryCal gas flow meter (BIOS, $500 \mathrm{ml} / \mathrm{min}$ ) and was recorded at the beginning and the end of the sampling period. Before subjected to chemical analysis, each sample was spiked with 120ng of gas-phase 1-Bromo-3 Fluoro-Benzene (BFB), which was used as the internal standard (ISTD) in the quantification method.

Analytes were thermally desorbed from the sampling tubes using a thermodesorption auto-sampler (Model TDSA2; Gerstel), a thermo-desorption oven (Model TDS3, Gerstel), and a cooled injection system (Model CIS4; Gerstel). Desorption was performed in splitless mode where the desorbed analytes were refocused on the cooled injection system prior to injection. Desorption temperature for the TDS started at $30{ }^{\circ} \mathrm{C}$ with a 0.5 minute delay followed by a $60{ }^{\circ} \mathrm{C}$ ramp to $250{ }^{\circ} \mathrm{C}$ and a 4 minute hold time. The cooled injection system was fitted with a Tenaxpacked glass liner (P/N 013247-005-00; Gerstel) that was held at $-10{ }^{\circ} \mathrm{C}$ throughout desorption and then heated within 0.2 minutes to $270{ }^{\circ} \mathrm{C}$ followed by a 3-minute hold time. Compounds were resolved on a GC (Series 6890Plus; Agilent Technologies) equipped with a 30 meter HP1701 14\% Cyanopropyl Phenyl Methyl capillary column (Model 1909IU-233;- Agilent Technologies) with helium flow of $1.2 \mathrm{~mL} / \mathrm{min}$. The initial temperature of the oven was $-10{ }^{\circ} \mathrm{C}$ held for 0.5 minutes then ramped at $5{ }^{\circ} \mathrm{C} / \min$ to $40{ }^{\circ} \mathrm{C}$ then $3{ }^{\circ} \mathrm{C} / \mathrm{min}$ to $140{ }^{\circ} \mathrm{C}$ and finally at 10 ${ }^{\circ} \mathrm{C} / \mathrm{min}$ to $250{ }^{\circ} \mathrm{C}$ and held for 10 minutes.

The resolved analytes were quantified using electron impact mass spectrometry, (MS System 5973; Agilent technologies), with mass to charge ratio limits of $44.0 \mathrm{~m} / \mathrm{z}$ and $450.0 \mathrm{~m} / \mathrm{z}$. The MS was operated in full scan mode with a solvent delay of 3.00 minutes. Compounds were initially identified using NIST mass spectral search program for the NIST/EPA/NIH mass 
spectral library (version 2.0d build April 26, 2005) with identity confirmed and quantified using pure standards. When pure standards were not available, the analyte was reported in terms of toluene equivalence by comparing the instrument response for the total ion chromatogram (TIC) of the chemical to a multipoint calibration of TIC response for toluene.

\section{Active Sampling for Carbonyl}

The volatile carbonyls including formaldehyde, acetaldehyde and acetone are quantified using USEPA Method TO-15 [19]. As with the VOC samples, the air was drawn directly from the chambers during sampling. The sampling rate was maintained at less than $80 \%$ of the total air flow through the chamber to prevent backflow of unfiltered air into the chamber during testing. The sample air passed through silica gel cartridges coated with 2,4-dinitrophenyl-hydrazine, which quantitatively reacts with the carbonyl functional group effectively trapping the aldehydes and other low molecular weight carbonyl compounds. A peristaltic pump was used to pull the air through the cartridge at a rate of approximately at $800 \mathrm{~mL} / \mathrm{min}$ for 1 hour. The flow was measured using a DryCal gas flow meter $(\mathrm{BIOS}, 5 \mathrm{~L} / \mathrm{min})$ and recorded at the beginning and the end of the sampling period. Prior to analysis, sample cartridges were eluted with $2 \mathrm{ml}$ of high purity acetonitrile and the effluent was brought to a final volume of $2 \mathrm{ml}$. The extract was analyzed by high-performance liquid chromatography (HPLC) (1200 Series; Agilent Technologies). The HPLC was fitted with a C18 reverse phase column and run with 65:35 H2O: Acetonitrile mobile phase at $0.35 \mathrm{~mL} /$ minute and UV detection at $360 \mathrm{~nm}$. Multipoint calibrations were prepared for the target analytes using commercially available hydrazone derivatives of formaldehyde, acetaldehyde and acetone.

\section{Data Analysis}

The emission factors for each sample material were calculated using the information collected from each chamber at steady state conditions. The steady-state form of the mass balance equation for calculating area-specific emission factors, $E F_{\mathrm{i}},\left(\mu / \mathrm{m}^{2} / \mathrm{h}\right)$ for chemical $i$ in a well-mixed system is

$$
E F_{i}=\frac{F \times\left(C_{i}-C_{B i}\right)}{A_{m}}
$$


where $F\left(\mathrm{~m}^{3} / \mathrm{h}\right)$ is the ventilation flow rate, $A_{m}\left(\mathrm{~m}^{2}\right)$ is the exposed surface area of test material $m$, $C_{i}\left(\mu \mathrm{g} / \mathrm{m}^{3}\right)$ is the measured steady state concentration of chemical $i$ in the chamber and, $\mathrm{C}_{\mathrm{Bi}}(\mu \mathrm{g} /$ $\mathrm{m}^{3}$ ) is the background concentration in the chamber when empty. The air change rate in the chamber, $A C H(1 / \mathrm{h})$ is the ventilation rate divided by the chamber volume $(F / V)$ and the loading factor of the material, $L\left(\mathrm{~m}^{2} / \mathrm{m}^{3}\right)$, is the exposed surface area of test material divided by the chamber volume, where the equation mentioned above can be rearranged to the form

$$
E F_{i}=\frac{A C H \times\left(C_{i}-C_{B i}\right)}{L_{m}}
$$

which is the equation used to calculate material specific emission factors for all materials in this study. The steady-state mass balance relationship can also be used to convert the material specific emission factors to approximate room concentrations using Equation 3

$$
C_{i}=\frac{E F_{i} \times L_{m}}{A C H \times 0.9}
$$

Where $L_{m}$ is now the loading factor for the specific material type in the building or room, and the factor 0.9 is an approximate correction of the total room volume to the volume of accessible space. Further details of this approach can be found in reference [15].

\section{RESULTS AND DISCUSSION}

All materials were initially tested after only 24-hours of conditioning time. Prior to conditioning, the materials had been tightly wrapped in foil and packaged individually in resealable plastic bags during shipping so the initial emissions were expected to be elevated. The purpose of this in initial testing was to identify the chemicals in the emission stream. A total of forty chemicals were identified in the emission stream from the six materials tested. All chemicals are listed in Table 2 along with steady state concentrations measured after 24-hours of conditioning. All values are listed in Table 2 for comparision but values above the typical method limit of quantification (LOQ) of $0.5 \mu \mathrm{g} / \mathrm{m}^{3}$ are listed in bold text.

The plastic material from the hydroponic drum was tested as received without sealing the back and sides so the exposed area was approximately double that of the other materials. The 
initial measurements found that except for hexadecane and tetradecane, most of the VOCs from the plastic material, including the aldehdyes, were near or below the minimum detection limit. Therfore, the plastic is not likely a source of indoor contaminants in the indoor environment of the PBC. The drywall material produced a number of elevated VOCs with two (benzyl alcohol and propylene glycol) that exceeded the linear range of the analytical method. Drywall is typically a low VOC material $[17,20]$ although fresh coatings such as paint or plaster can emitt VOCs during curing. The drywall samples tested in this study appear to be freshly painted because the edges were sealed with paint. This might explain the elevated propylene glycol and benzyl alcohol. The new wood paneling had very high levels of formaldehyde both with and without polish although the polished panel had the hightest levels of formaldehyde overall. However, the unpolished new wood panel produced a wider variety and higher levels of VOC in the emissions. The old wood paneling produced much lower levels of formaldehyde and the levels of VOCs in general were similar both with new and old polish.

After the initial tests were completed to identify the target chemicals in the emission stream, the materials were returned to the conditioning chambers for approximately six more days before measuring the emission factors. Concentrations for the plastic material from the hydroponic drum remained low in the second test so emission factors are not reported for the plastic hydroponic drum material. The standard emission factors determined for the wood paneling and drywall materials are reported in Table 3. The formaldehyde emissions from new wood with new polish were still significantly elevated after 7 days but we suspected that the combination of polish and storage may have increased the time needed for the emission factor to drop to a relativily constant level. To address this, we continued to condition the new wood with new polish for an additional week (total 15 days total) and re-tested. The additional time needed to condition the new wood with new polish may have been due to a higher capacity of the polish coating for accumulating formaldehyde during storage. This possibility was tested and is discussed further below.

The standard emission factors for the materials from the $\mathrm{PBC}$ are summarized in Table 3. Several of the chemicals that were initially detected in the materials were no longer detectable in the emission stream after a week of conditioning and are therfore not listed in Table 3. The painted drywall continued to have extremely high levels of benzyl alcohol and propylene glycol 
as well as quantifiable levels of several other aldehydes (formaldehyde, benzaldehyde, decanal and nonanal), alcohols and esters that may be related to the coating material and/or sorbed into the drywall matrix from the environment. The wood paneling material presented a mix of VOCs depending on if the polish and/or wood were new or old as illustrated in Figure 3. Figure 3 lists the sum of all emission factors for VOC presented as stacked colums with the largest overall emission factors listed in decreasing order from bottom to top on the figure legend. Emission factors listed in Table 3 that are below the approximate limit of quantification of $1.65 \mu \mathrm{g} / \mathrm{m}^{2} / \mathrm{h}$ are not included in Figure 3. Overall the drywall material had the highest sum of individual emission factors $\left(516 \mu \mathrm{g} / \mathrm{m}^{2} / \mathrm{h}\right)$ with the paneling material emitting $134,129,33$ and $7\left(\mu \mathrm{g} / \mathrm{m}^{2} / \mathrm{h}\right)$ for the new wood no applied polish, old wood new polish, new wood new polish and old wood old polish, respectivily.

Formaldehyde emissions for the old wood paneling with new and old polish, and the drywall were all similar ranging from $10 \mu \mathrm{g} / \mathrm{m}^{2} / \mathrm{h}$ (drywall and old wood with new polish) to 22 $\mu \mathrm{g} / \mathrm{m}^{2} / \mathrm{h}$ (old wood with old polish). For the new wood, the formaldehyde emissions were approximately an order of magnitude higher than the other materials for both the polished and unfinished surfaces. The emission results for formaldehyde are illustrated in Figure 4 showing that the polish coating does not seem to significantly change the measured emission factors when the age of the wood paneling is taken into consideration. For old wood, the new polish slightly reduces the emission factor while for new wood the polish increases the emission factor slightly but the difference is likley more a function of the age of the wood than the polish. For example, given the old wood where the emissions are already low, adding the new polish may provide an apparent sink for the formaldehyde as it accumulates in the coating. In contrast, for the new wood, the initial emission rate is high and the coating may simply add a diffusion layer that increases the time that the emission from the wood paneling takes to drop to a constant level. With or without the coating, the new wood is clearly the major source of formaldehyde emissions among the materials tested.

The aging of the formaldehyde emissions and the affect of the polish coating were tested further by removing the backing plate from the new wood with new polish after the initial conditioning and testing period was complete and reversing the material to expose the unfinished face. Our premise was that the formaldehyde diffuses to and accumulates at the surface of the 
material when the surface is covered so the initial emissions after uncovering the surface are expected to be high then drop with time towards an constant value. The results are illustrated in Figure 5. The initial test of the polished side was repeated 4 times over 15 days. To test the emissions of aldehydes from the unfinished side of the same new wood material, the sample was flipped to expose the unfinished side and the polished side was sealed and the sample was returned to the test chamber (without conditioning) to test the unfinished face. The first measurement found formaldehyde emissions from the unfinished face significantly in excess of the polished side but the emissions decreased rapidily over the next week. The material was flipped again exposing the poished side again that had been sealed for a week and the emission factor doubled ( $109 \mu \mathrm{g} / \mathrm{m}^{2} / \mathrm{h}$ to $217 \mu \mathrm{g} / \mathrm{m}^{2} / \mathrm{h}$ ) but resumed dropping over the next day. Overall, the results indicate that the emission factor of formaldehyde from the new wood with new polish is approaching that of the new wood with no applied polish over time.

The standard emission factors for formaldehyde from each of the main wall surface materials (drywall, old wood and new wood) listed in Table 3 are compared to field measured values for the PBC building that were collected previously using Equation 3 along with the building parameters listed in Table 4 . The results are listed in Table 5 for each material and each floor as a range of concentrations estimated with $\mathrm{ACH}$ values representing the maximum and $50 \%$ of the maximum accounting for the fact that the demand response system will likely run the ventilation at less than the maximum value. These ranges are summed for the total wall area based on loading factors for each material and the range of total concentraions are compared to the measurements in the last row of the table. Assuming no other significant loss pathways for formaldehyde, the three primary wall materials can easily account for the measured concentrations.

\section{CONCLUSION}

From the building materials that were supplied to LBNL for testing, it was determined that the formaldehyde levels measured in the PBC can be accounted for by emissions from old wood paneling, painted drywall and new wood paneling. Overall, the highest emitter of formaldehyde was new wood paneling and, although the surface polish affected the time to steady state, polish did not generally increase the amount of formaldehyde released. The aging of 
the new paneling will likely result in a reduction in formaldehyde emissions to a value that is similar to that of the old paneling. This reduction of emission with time has been observed in a number of buildings [12]. It is possible that the wood polish provides a reservoir for indoor contaminants as indicated by the fact that a number of VOCs and aldehydes detected after the materials were conditioned for only a day dropped below detection levels after a week of conditioning, indicating that these contaminants were not indigenous to the materials being tested but had partitioned into these materials from the environment. Although the polish was not found to contribute to formaldehyde emissions, the polish does contribute to VOC emissions for some chemicals as seen by comparing the polished and unpolished side (data not shown) of one of the materials. Painted surfaces of drywall were also found to be significant contributors to a range of VOCs particularly those related to the coating. It may be that the coating on the drywall material was fresh and the emissions will drop with time as the paint cures. Nonetheless, the painted drywall sample tested during this project clearly had elevated levels of VOCs related to the coating.

This study considered only the materials that were provided to LBNL for testing. There may be other sources present in the building, both continuous and intermittent, which may influence the indoor concentrations of chemicals. Considering only the materials included in this study, the modeling indicates that formaldehyde concentrations on the fifth floor should be lower than that on the third floor but the measurements collected in the previous field study were similar. This may indicate that other unidentified sources or contaminant removal pathways are present in the building.

The tradeoff between having high quality aesthetically pleasing materials in the indoor environment and introducing unanticipated contaminants into the space is a difficult one. Aged materials seem to contribute minimal amounts of VOCs and aldehdyes but better understanding of the temporal characteristics of the aging process would provide important opportunities to optimize the ventilation and air treatment options after renovations or during episodic increases in chemical loading. In addition, further work should consider potential secondary source of contaminants such as the degradation of alkenes and higher molecular weight carbonyls under UV light treatment in the air handling system or potential degradation of polish and other coating materials. 


\section{REFERENCES}

[1] Paharpur Buisness Centere \& Software Technology Incubator Park Indoor Air Quality. Retrieved from http:// http://www.pbcnet.com/

[2] M.G. Apte and J.S. Apte. 2010. "A Pilot Study of the Effectiveness of Indoor Plants for Removal of Volatile Organic Compounds in Indoor Air in a Seven-Story Office Building" LBNL-3368E, Lawrence Berkeley Laboratory, University of California, Berkeley, CA 94720

[3] Wolverton, B.C., R.C. McDonald, and E.A. Watkins, Jr. 1984. "Foilage plants for removing indoor air pollutants from energy-efficient homes. Econ. Bot. 38: 224-228.

[4] Wolverton, B.C. , A. Johnson, and K. Bounds. 1989. "Interior landscape plants for indoor air pollution abatement. NASA/ALCA Final Report. Plants for Clean Air Council, Mitchellville, MD.

[5] Hodgson A.T., J.M Daisey, and R.A. Grot (1991) "Sources and source strengths of volatile organic compounds in a new office building" Journal of Air an dWaste Management Association. 41:1461-1468.

[6] Hodgson A.T. A.F. Ruud, D. Beal and S. Chandra (2000) "Volatile organic compound concentrations and emission rates in new manufactured and site-built houses" Indoor Air. 10:178-192.

[7] Zuraimi M.S., K.W. Tham and S.C. Sekhar (2004) "A study on the identification and quantification of sources of VOCs in 5 air-conditioned Singapore office buildings" Building and Environment 39:165-177.

[8] Maddalena R., M. Russell, D.P. Sullivan and M.G. Apte (2009) "Formaldehyde and Other Volatile Organic Chemical Emissions in Four FEMA Temporary Housing Units" Environmental Science and Technology. 43:5626-5632. 
[9] Hodgson A.T. and H. Levin (2003) "Volatile organic compounds in indoor air: A review of the concentrations measured in north America since 1990" Lawrence Berkeley National Laboratory. LBNL Report Number 51715.

[10] Chao C.Y., and C.Y. Chan (2001) "Quantification of indoor VOCs in twenty mechanically ventilated buildings in Hong Kong” Atmospheric Environment 35:5895-5913.

[11] Hippelein H. (2004) "Background concentrations of individual and total volatile organic compounds in residential indoor air of Schleswig-Holstein, Germany" Journal of Environmental Monitoring 6:745-752.

[12] Park J.S. and K. Ikeda (2006) "Variatioins of formaldehyde and VOC levels during three years in new and older homes" Indoor Air 16:129-135.

[13] Salthammer T., S. Mentese and R. Marutzky (2010) "Formaldehyde in the Indoor Environment" Chemical Reviews 110:2536-2572.

[14] Logue J.M., T.E. McKone, M.H. Sherman and B.C. Singer (2010) "Hazard assessment of chemical air contaminants measured in residences" Lawrence Berkeley National Laboratory LBNL Report Number 3650-E.

[15] California Department of Health Services (2004) "Standard Practice for the Testing of Volatile Organic Emissions from Various Sources Using Small-Scale Environmental Chambers. Environmental Health Laboratory Branch. July 15, 2004

[16] ASTM International (2002) "Standard Test Method for Determining Formaldehyde Concentration in Air from Wood Products Using a Small Scale Chamber. Designation: D 6007-02

[17] Maddalena, R., Russell, M., \& Apte, M. G. (2010) Small Chamber Measurements of Chemical Specific Emission Factors for Drywall: Interim Project Report to Sponsor Environmental Energy Technologies Division Ernest Orlando Lawrence Berkeley National Laboratory

[18] Woolfenden, E.A., W.A. McClenny (1999) Method TO-17. Determination of Volatile Organic Compounds in Ambient Air Using Active Sampling onto Sorbent Tubes. In 
Compendium of Methods for Determination of Toxic Organic Compounds in Ambient Air. Second Edition. Office of Research and Development, U.S. Environmental Protection Agency: Research Triangle Park, NC, 1996. EPA/625/R-96/010b

[19] McClenny, W.A., M.W. Holdren (1999) Method TO-11. Determination of Formaldehyde in Ambient Air Using Adsorbent Cartridge Followed by High Performance Liquid Chromatography (HPLC) [ActiveSampling Methodology]:. In Compendium of Methods for Determination of Toxic Organic Compounds in Ambient Air. Second Edition. Office of Research and Development, U.S. Environmental Protection Agency: Research Triangle Park, NC, 1996. EPA/625/R-96/010b

[20] Alevantis L. (2003) "Building Material Emission Study" California Department of Health Services, Report prepared for the California Integrated Waste Management Board, Publication \#433-03-015, November 2003 
Table 1. PBC Building Material Samples

\begin{tabular}{lll}
\hline \multicolumn{1}{c}{ Sample Type } & \multicolumn{1}{c}{ Description } & Identification \\
\hline Wood & New plywood paneling with & NWNP \\
& new polish ${ }^{1}$ & \\
Wood & New plywood paneling with & NW \\
& no applied polish (bare wood $)$ & \\
Wood & Old plywood paneling $(\sim 20$ & OWNP \\
& years $)$ with new polish & \\
Wood & Old plywood paneling $(\sim 20$ & OWOP \\
& years $)$ with old polish & \\
Gypsum board & Drywall with painted finish. & GB \\
& All surfaces of the sample & \\
& including edges were painted & HDP \\
High Density Plastic & Hydroponic drum material & \\
& used in air cleaning system & \\
\hline
\end{tabular}

\footnotetext{
${ }^{1}$ Both the front face (polished) and the back face (unpolished) of this material were tested over the course of the study to further understand the contribution of the polish to the emission stream and the affect that polish might have on emissions from the underlying material.
} 
Table 2. Measured air concentrations $\left(\mu \mathrm{g} \mathrm{m}^{-3}\right)$ of identified chemicals in test chamber after 24hour conditioning period.

\begin{tabular}{|c|c|c|c|c|c|c|}
\hline \multirow[b]{3}{*}{ Chemical Name } & \multicolumn{6}{|c|}{ Material Description } \\
\hline & \multicolumn{2}{|c|}{ Old Wood } & \multicolumn{2}{|c|}{ New Wood } & \multirow{2}{*}{$\begin{array}{l}\text { DryWall } \\
\text { Painted }\end{array}$} & \multirow{2}{*}{$\begin{array}{c}\text { Plastic } \\
\text { Hydro- } \\
\text { Drum }\end{array}$} \\
\hline & $\begin{array}{c}\text { Old } \\
\text { Polish }\end{array}$ & $\begin{array}{l}\text { New } \\
\text { Polish }\end{array}$ & $\begin{array}{c}\text { No } \\
\text { Polish }\end{array}$ & $\begin{array}{l}\text { New } \\
\text { Polish }\end{array}$ & & \\
\hline Formaldehyde & $9.86^{\mathrm{a}}$ & 5.75 & 50.37 & 315.91 & 4.74 & 0.19 \\
\hline Acetaldehyde & 1.22 & 0.49 & 0.16 & 0.20 & 0.53 & 0.53 \\
\hline Acetone & 0.36 & 1.39 & $\mathrm{nd}^{\mathrm{c}}$ & nd & nd & nd \\
\hline Benzaldehyde & 0.11 & 0.13 & 1.03 & 0.08 & 7.73 & 0.14 \\
\hline Benzyl Alcohol ${ }^{b}$ & 0.40 & 0.46 & 47.54 & 0.05 & $>\mathbf{8 0}^{\mathrm{d}}$ & nd \\
\hline 1-Butanol & 1.42 & 1.48 & 2.26 & nd & 2.38 & nd \\
\hline 2-Butanol & 0.87 & 0.88 & 2.02 & nd & 0.78 & nd \\
\hline 2-Butoxyethanol & 0.85 & 1.10 & 2.80 & nd & 0.84 & nd \\
\hline n-Butyl Laurate & nd & 1.01 & 0.16 & 0.43 & nd & nd \\
\hline 3-Carene & 0.07 & 0.08 & 0.12 & 0.04 & 37.83 & 0.23 \\
\hline Decamethylcyclopentasiloxane & 0.41 & 0.01 & 0.07 & 0.04 & 0.21 & 0.01 \\
\hline Decanal & 1.10 & 0.30 & 0.63 & 0.14 & 0.18 & nd \\
\hline 1,4-Dichlorobenzene & 0.14 & 0.10 & 0.10 & 0.05 & 2.49 & 0.22 \\
\hline Diethylphthalate & 0.14 & 0.13 & 0.26 & 0.23 & 0.15 & 0.03 \\
\hline \multicolumn{7}{|l|}{ Dodecanoic acid, 1-methylethyl } \\
\hline ester & nd & 0.51 & 0.55 & 0.76 & nd & 0.13 \\
\hline Ethanol, 2-(2-butoxyethoxy)- & nd & 0.14 & 9.21 & nd & 4.30 & nd \\
\hline Ethylbenzene & 0.02 & nd & 0.05 & nd & 0.04 & nd \\
\hline Hexadecane & nd & nd & nd & nd & nd & 1.00 \\
\hline Hexanal & 0.20 & 0.13 & 0.42 & 0.48 & 0.56 & 0.02 \\
\hline Hexanedioic acid, dimethyl ester & 27.36 & 75.97 & 28.26 & 0.27 & 0.22 & 0.13 \\
\hline D-Limonene & 0.10 & 0.06 & 0.10 & 0.04 & 8.70 & 0.10 \\
\hline Methylene Chloride & 0.28 & 0.52 & 0.19 & 0.19 & 0.04 & nd \\
\hline Naphthalene & 0.22 & 0.28 & 0.28 & nd & 0.55 & 0.08 \\
\hline Nonanal & 3.82 & 2.55 & 3.40 & 0.66 & 2.17 & 0.48 \\
\hline Octanal & 0.32 & 0.16 & nd & 0.03 & nd & nd \\
\hline Pentanedioic acid, dimethyl ester & 4.68 & 7.89 & 6.36 & nd & nd & nd \\
\hline Phenol & 0.89 & 1.41 & 3.41 & 1.34 & 0.63 & nd \\
\hline$\alpha$-Pinene & 0.10 & nd & nd & nd & 1.88 & nd \\
\hline $\begin{array}{l}\text { Propanoic acid, 2-methyl, 3- } \\
\text { hydroxy-2,4 }\end{array}$ & 0.37 & 1.21 & 18.74 & 1.09 & 16.08 & 0.72 \\
\hline 2-Propanol, 1-methoxy- & 1.98 & 2.04 & 1.86 & nd & nd & nd \\
\hline Propylene Glycol & nd & nd & nd & nd & $>80^{\mathrm{d}}$ & nd \\
\hline Styrene & nd & nd & nd & nd & 0.05 & nd \\
\hline$\alpha$-Terpineol & 0.70 & 0.19 & 0.29 & 0.12 & 0.47 & nd \\
\hline Tetradecane & 0.12 & 0.73 & 0.98 & 0.49 & 0.40 & 4.47 \\
\hline Toluene & 0.82 & 0.62 & 1.17 & 0.35 & 2.33 & nd \\
\hline TXIB isomer ${ }^{\mathrm{e}}$ & 0.18 & 0.11 & 0.45 & 0.12 & 0.57 & 0.09 \\
\hline$T X I B^{\mathrm{e}}$ & 0.18 & 1.39 & 9.72 & 0.85 & 9.32 & 0.17 \\
\hline unknown phthalate & 0.03 & nd & nd & nd & nd & nd \\
\hline $\mathrm{m} / \mathrm{p}$-Xylene & 0.08 & 0.07 & 0.27 & nd & 0.16 & nd \\
\hline o-Xylene & 0.08 & 0.07 & 0.22 & nd & 0.20 & nd \\
\hline
\end{tabular}

${ }^{a}$ Approximate limit of quantification (LOQ) value for the chamber testing was $0.5 \mathrm{ug} / \mathrm{m}^{3}$. All data are listed for comparison but values above the LOQ are listed in bold text; ${ }^{\mathrm{b}}$ Italicized chemicals are reported as toluene equivalents; ${ }^{\mathrm{c}} \mathrm{An}$ "nd" means the value was not detected or was below the blank subtract; ${ }^{\mathrm{d}}$ Concentration is beyond the linear range of the calibration curve and/or instrument response; ${ }^{\mathrm{e}}$ TXIB is 2,2,4-Trimethyl-1,3-pentanediol diisobutyrate 
Table 3. Standard Emission Factors $\left(\mu \mathrm{g} \mathrm{m}^{-2} \mathrm{~h}^{-1}\right)$ for PBC materials determined after 7-days conditioning

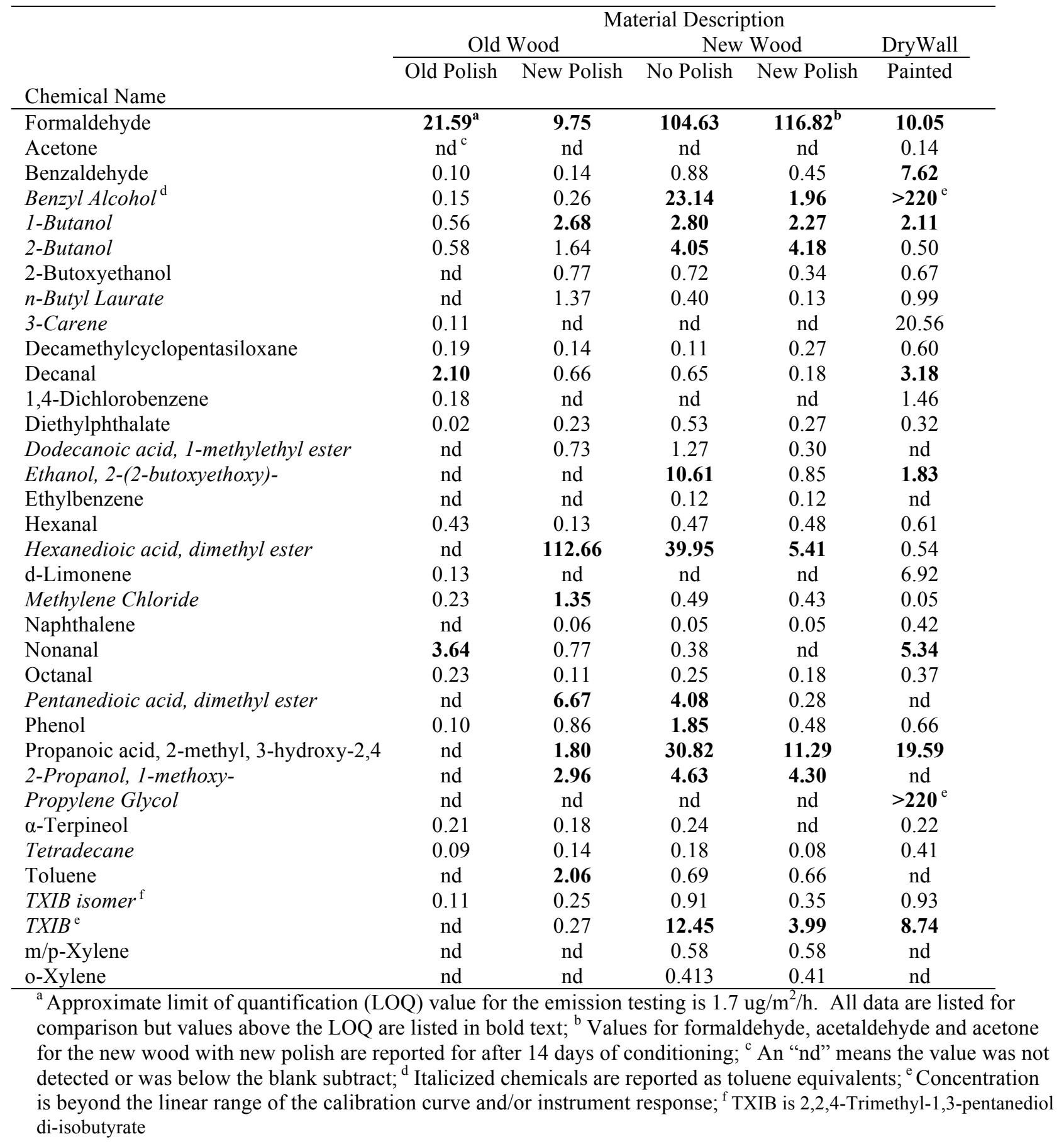


Table 4. Building specific parameters used to estimate room air concentrations

\begin{tabular}{llll}
\hline Description of parameter & units & Third Floor & Fifth Floor \\
\hline Estimated floor area & $\mathrm{ft}^{2}$ & 7200 & 7200 \\
Assumed ceiling height & $\mathrm{ft}^{3}$ & 9 & 9 \\
Absolute volume & $\mathrm{m}^{3}$ & 1835 & 1835 \\
Ventilation (maximum) & $\mathrm{m}^{3} / \mathrm{h}$ & 1699 & 2854 \\
$\mathrm{ACH}^{\mathrm{a}}$ (range) & $1 / \mathrm{h}$ & $0.5-1.02$ & $0.9-1.72$ \\
Area of new wood with new polish & $\mathrm{m}^{2}$ & 46 & 18 \\
Area of old wood with new or old polished & $\mathrm{m}^{2}$ & 2240 & 906 \\
Area of drywall & $\mathrm{m}^{2}$ & 910 & 1106 \\
Loading factor new wood with new polish & $\mathrm{m}^{2} / \mathrm{m}^{3}$ & 0.025 & 0.010 \\
Loading factor old wood with new or old polished & $\mathrm{m}^{2} / \mathrm{m}^{3}$ & 1.22 & 0.49 \\
Loading factor drywall & $\mathrm{m}^{2} / \mathrm{m}^{3}$ & 0.50 & 0.60 \\
\hline
\end{tabular}

${ }^{a}$ air change rate adjusted assuming a factor of 0.9 for volume of inaccessible space in room. Maximum values provided for $\mathrm{PBC}$ and assumption made of $50 \%$ minimum flow in demand response mode.

Table 5. Comparison of estimated to measured formaldehyde in PBC

\begin{tabular}{|c|c|c|c|}
\hline $\begin{array}{r}\text { Material specific contribution to estimated } \\
\text { concentration }\end{array}$ & units & Third Floor & Fifth Floor \\
\hline New wood with new polish & $\mu \mathrm{g} / \mathrm{m}^{3}$ & $3-6$ & 1 \\
\hline Old wood with new or old polish & $\mu \mathrm{g} / \mathrm{m}^{3}$ & $19-37$ & $4-9$ \\
\hline Drywall & $\mu \mathrm{g} / \mathrm{m}^{3}$ & $5-10$ & $4-7$ \\
\hline Range of total estimated concentration & $\mu \mathrm{g} / \mathrm{m}^{3}$ & $26-53$ & $9-17$ \\
\hline Measured values on each floor ${ }^{\mathrm{a}}$ & $\mu \mathrm{g} / \mathrm{m}^{3}$ & $20,27,29,30$ & $20,25,27,29$ \\
\hline
\end{tabular}

${ }^{\mathrm{a}}$ Measured values reported in [2] 

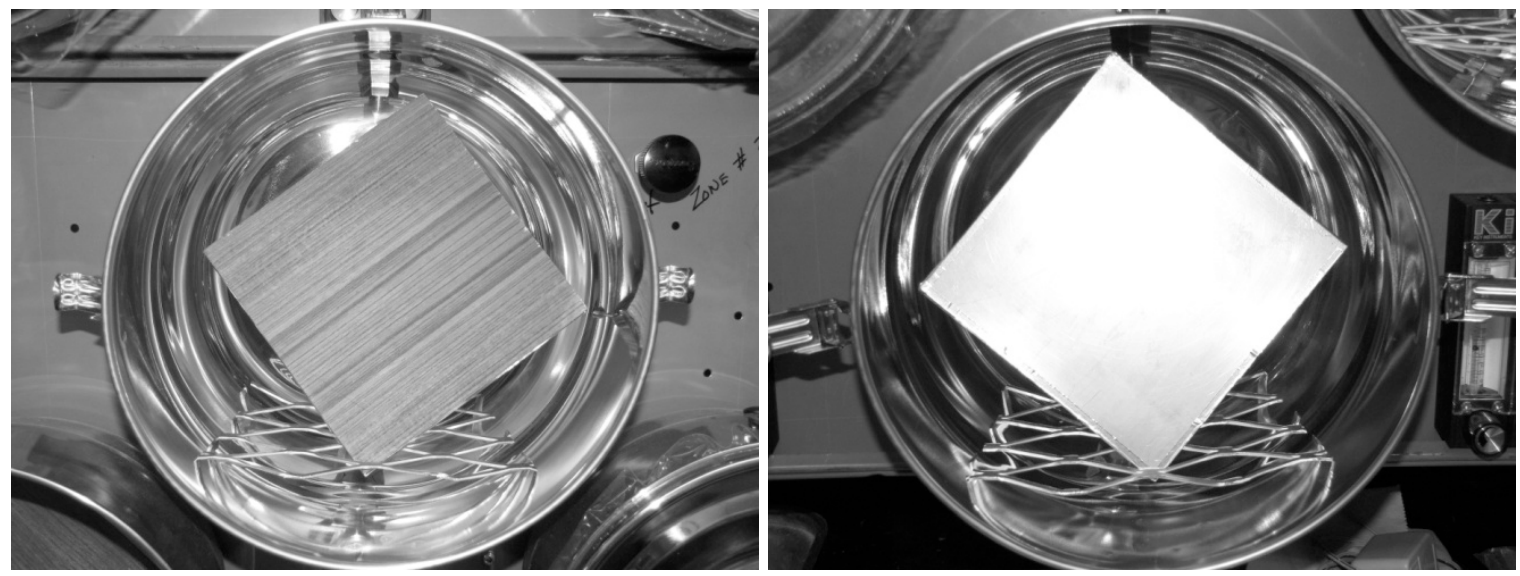

Figure 1. Example of prepared material samples installed in conditioning chambers prior to testing. Chambers are shown with lids removed.

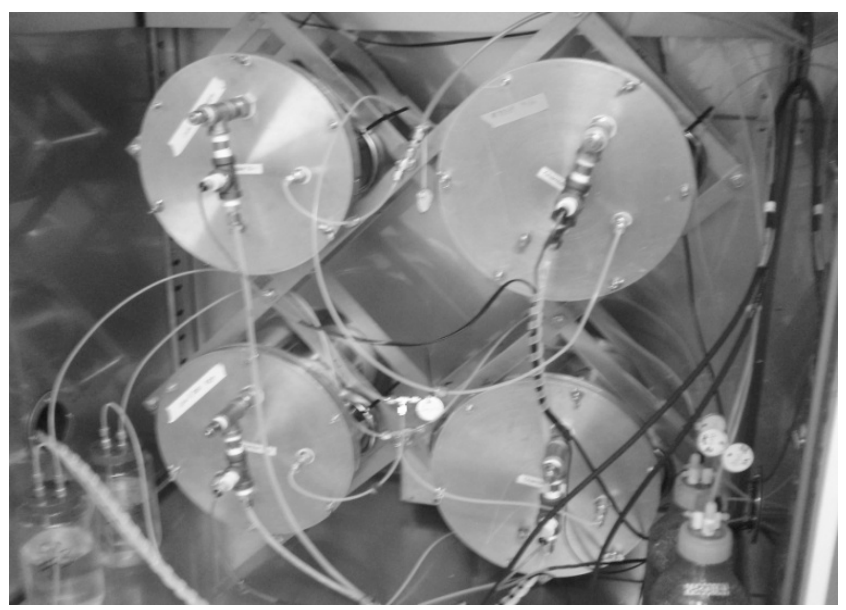

Figure 2. Photograph of emission chambers housed inside controlled environment oven. 


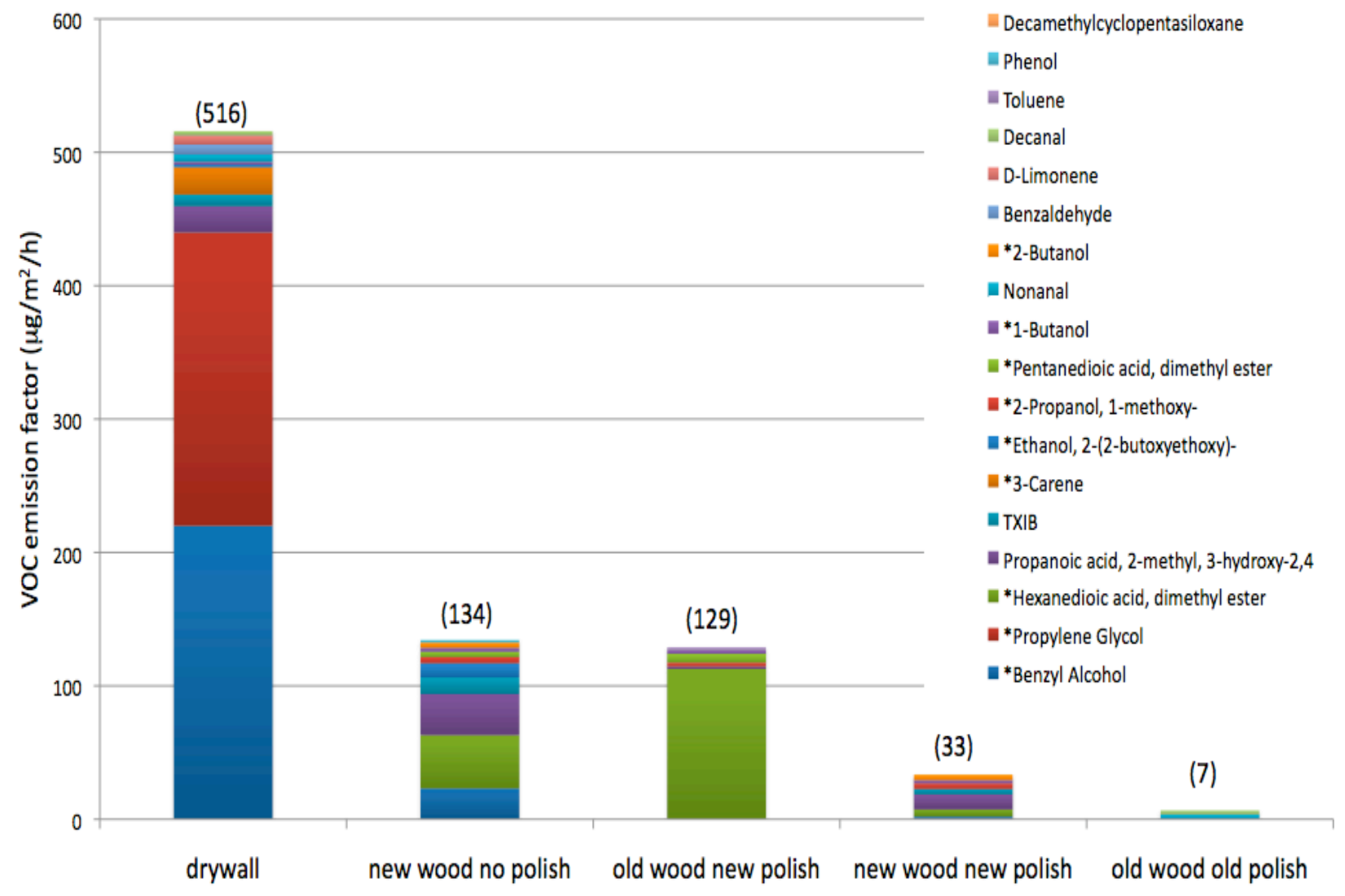

Figure 3. Total VOC emission factors as determined by the methods described in this report (listed in parenthesis above each column) for each material. The legend for the stacked columns is presented in order of decreasing contribution to the total emission stream from bottom to top. The results for formaldehyde are listed separately (see Figure 4) and are not included in this chart. 


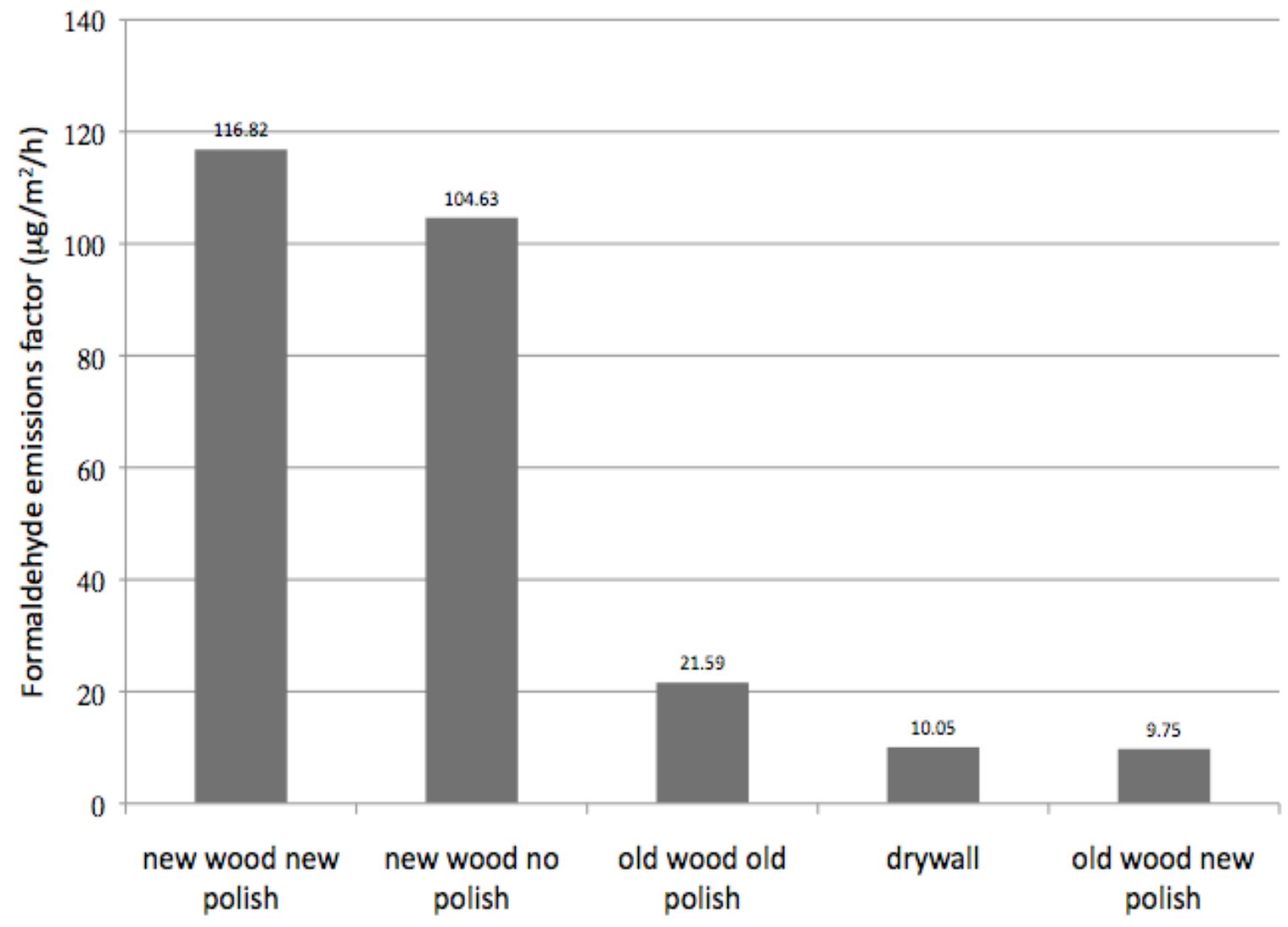

Figure 4. Comparison of formaldehyde emission from the different wall covering materials showing that the new wood is the primary source of formaldehyde and the use of polish does not significantly affect the measured emission factors. Actual values of the emission factors are listed above the column. New wood with new polish was aged 15 days while the other materials were aged 7 days. 


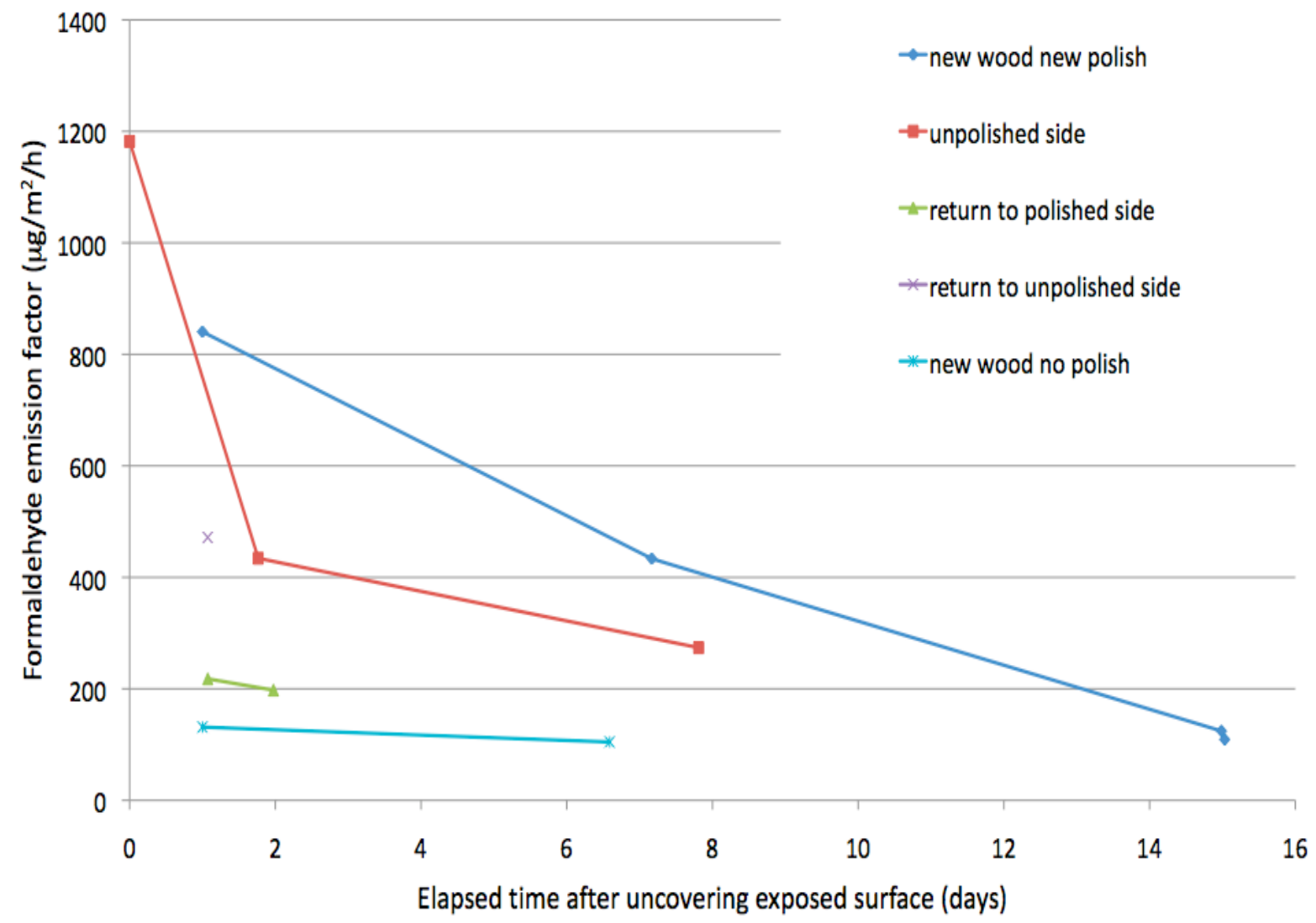

Figure 5. Aging of formaldehyde emissions for polished and unfinished surface of new wood compared to the emissions from the new wood sample with no applied polish. The experiments were run in the order 1) new wood new polish (diamonds) and new wood no polish (asterisk); 2) unpolished side (squares); 3) return to polished side of new wood new polish (triangle); 4) return to unpolished side (cross). During conditioning and testing of the polished side, the unpolished side was covered and visa versa. 